\title{
Ambivalent Views on Political News
}

\author{
ANKER BRINK Lund
}

Political decision making and the production of news are interdependent social processes in representative democracies. Ideally, news media and political institutions are supposed to provide checks and balances placing public opinion at the very core of policymaking (Cook, 1998; Schudson, 1996).

For several decades, however, critical media research has warned against news media serving as powerful tools for propaganda (e.g. Lippmann, 1922/1998; Fallows, 1996) and potential threats to communicative constitution of public opinion (e.g. Habermas, 1962/1989; Thompson, 1995). The crucial question behind these warnings has traditionally been to determine who actually set the political agenda (Rogers \& Dearing, 1987).

In spite of major research efforts in this area, scholars are at odds as to how opinion-formation actually takes place. In a Scandinavian context substantial government grants have recently enabled researchers to take a closer look at the complicated interplay between mass media and representative democracy. Norway was first in this area conduction the so called Maktutredningen (Investigation of Power) by the end of the 1970s (Høyer et al. 1982). Sweden followed ten years later (Petersson \& Carlberg, 1990), and after another decade Denmark is conducting a similar effort. This time not only in order to discus how the press, radio and television exercises power related to the political system, but also what journalist and other political stakeholders should do in this respect (Lund, 2002).

In telephone interviews with a representative sample of Danes, 17 years and older, 867 persons were polled as to their views on news media and de-

Department of Journalism, University of Southern Denmark, Campusvej 55, DK-5230 Odense M, abl@journalism.sdu.dk mocracy. In two adjunct studies, carried out in the same period (May 2001), identical questions were put to 811 journalists and 409 policymakers (holders of elected office and top-level officials in administrative institutions and articulate non-governmental organizations). In this article, we shall highlight principal points of agreement and contrast in the three surveys, focusing on views concerning political news and the role of journalism in a representative democracy. ${ }^{1}$

\section{Uses and Gratification}

Few empirical studies have compared the views of journalists, policymakers and the general public in order to determine the power of news as an integrated (and integrating) part of democratic processes. Research doing so indicates that political elites tend to distance themselves from the masses in terms of uses and gratification of news media (Berkowitz, 1997; Curran \& Gurevitch, 1994).

In the Danish context, however, the general public, journalists and policymakers seem to be far more homogeneous in terms of media consumption. The vast majority of Danes (91 per cent) partake of news reporting on a daily basis. The most commonly stated reason for keeping up with the news relates to the respondents roles as active citizens in a democracy. 93 per cent say that news reporting enables the individual citizen to form an opinion. Nearly eight in ten say that they keep up with the news in order to be able to take part in casual conversation with friends and colleagues. The same share also say that news reporting often supplies information that is useful to them personally.

These are essentially the same motives journalists and decision-makers mention. But the two elites put a little more emphasis on usefulness and a little 
less on conversation with friends and colleagues. Not surprisingly, professional motives are more common among journalists and policymakers than among the public at large. Only One Dane in five feels compelled to keep up with the news for workrelated reasons. Roughly one-third of all three groups mention the entertainment value of news reporting.

Television is the most widely used medium among the general population, whereas newspapers are the most important news sources among policymakers and journalists:

- All the policymakers surveyed, 97 per cent of the journalists, but only 56 per cent of the population read newspapers every day.

- 90 per cent of decision-makers, 85 per cent of journalists and 68 per cent of the population listen to radio newscasts each day.

- Eighty-four per cent of both decision-makers and journalists watch television newscasts each day. The corresponding figure among the population as a whole is 76 per cent.

- On a daily basis, only a small share of the population (5 per cent) uses the Internet as a source for political news. 25 per cent of policymakers and 39 per cent of journalists gather news from web-media every day.

Thus, we find that the Internet has not become a dominant news source, despite the fact that fully 71 per cent of the representative sample of the adult population have Internet access, either in the home or at work. This finding confirms a controversial thesis that despite the Internet's competitive advantages of speed and free access, traditional mass media are still the prime news carriers. Most Danes do not look upon online services as an integral part of the press in democratic society, neither with respect to news production nor for their personal news consumption.

\section{Priming and Framing}

A fundamental assumption in current research in political communication is that the power of news is executed through priming and framing events, i.e. not necessarily defining what the public should think, but rather effecting what issues the public is expected to think about - thereby rendering bias to evaluation of public opinion (Graber et al. 1998; Lund, 2001)
In Denmark, 42 per cent of the journalists interviewed feel that their profession, e.g. acting as primers and framers for political action, have too much influence. This view is shared by 59 per cent of the policy makers and 51 per cent of the public at large. Looking at the respective media, television is regarded as particularly (and unwarranted) influential.

When we inquire whether journalists should set the agenda for political debate, only among journalists do we find the unison answer: Yes. A majority of the policymakers and the general public do not consider this a democratic function of the media. Nonetheless, as many as 88 per cent of the policymakers and 73 per cent of the public at large feel that journalists do set the political agenda for discussions of public affairs. Here we encounter outright disapproval.

Notably, this mistrust of professional communicators as principal primers of policy agendas does not necessarily equal a nostalgic longing back to "the good old days" of less professionalism in public affairs. On the contrary, our findings reveal almost unanimous support for the opposite notion: A majority of respondents believe that democracy has been vitalized lately due to the loosening of ties between newspapers and political parties enabling journalists to be more investigative in political reporting.

More surprising, the significant increase in use of professional media advisors, the so-called "spin doctors", is welcomed by half of the Danes interviewed. They claim that the current use of professional press advisors may improve modern democracy. In marked contrast, three out of four journalists and two out of three policymakers find the increasing use of "spin doctors" troubling.

In comparison it is interesting to note that 77 per cent of the journalists and 68 per cent of the policymakers also state that opinion polls have too much influence over political decision making. In contrast, a majority of the general public finds the polls' influence "about right" (45 per cent) or "too little" (11 per cent).

We have approached the problem of opinion forming credibility by asking what respondents felt was the most important political issues at the time of the telephone interview. We asked all three samples to indicate an issue or problem that was of such importance that elected officials and legislators should do something about it. The advantage of this two step approach is that we register the respondents' views in specific relation to a subject he or she considers important. Such a procedure ought to 
Figure 1. Public Opinion (in percentage) of Institutional and Personal Influence on Political Decisions in Denmark

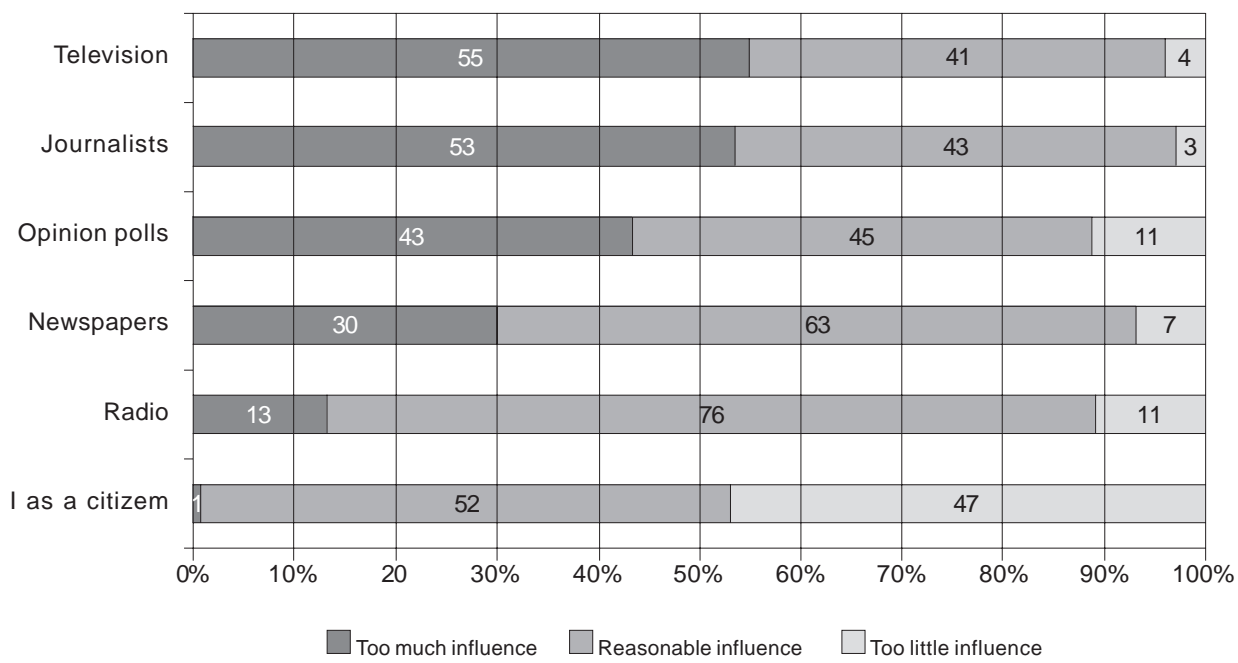

Figure 2. Journalists' Opinion (in percentage) of Institutional and Personal Influence on Political Decisions in Denmark

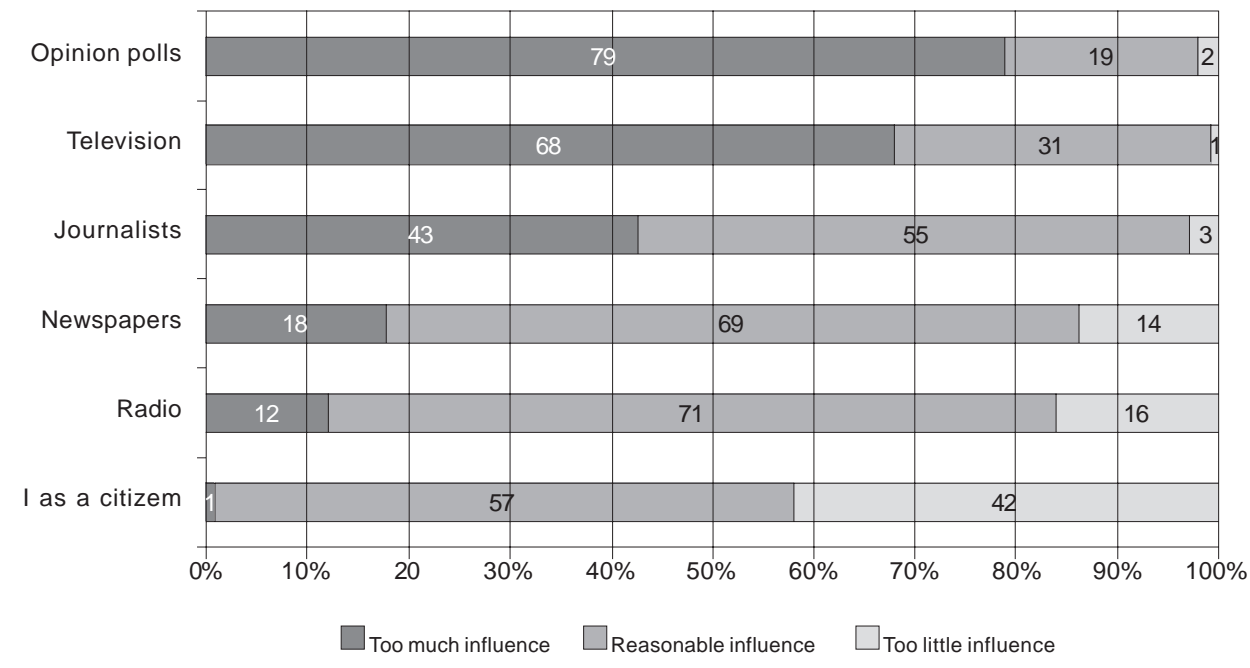

produce more valid data than asking for issues in general.

On the basis of this material we obtained three mutually related agendas. Not surprisingly, journalists consider news coverage more reliable that the other respondents. Among decision-makers a mere 49 per cent found news coverage of favoured issues reliable, and 46 per cent of the general public voiced similar views.
We may compare the findings to American studies (Altschull, 1995; Iyengar, 1991) defining a phenomenon known as "the spiral of cynicism" (Capella \& Jamieson, 1997), i.e. indicating that cynical media coverage in relation to politics produce cynical politicians and less politically interested citizens.

In terms of cynicism, the responses in the present studies are somewhat equivocal. The major- 
ity of respondents find news coverage "slanted" by the news media. Only one-third of the public consider that reporters have consulted the best sources on issues considered important. Such indicators may be interpreted as signs of a cynical trend. On the other hand, a considerable amount of credibility is given to mass mediated news coverage of political content. Consequently, we may venture the conclusion that the spiral of cynicism does not appear to be predominant in Danish politics compared to the United States.

A complementary indicator of cynicism (or lack thereof) is the degree of participation in democratic processes. In Scandinavia there is high election turnouts, but widespread concern about declining membership of political parties and NGOs. As an indicator of current interest in political processes we asked the Danish respondents how important it is to stay informed about political news - locally, nationally and internationally.

It appears that political involvement on all three levels surveyed is fairly weak. A majority (57 per cent) of the sample representing the general public do not consider it important to keep abreast of politics on any of the levels. Responses to these questions reveal marked differences between the public at large and the two professional polls.

Not surprisingly, policy makers are far more interested in public affairs at all three levels. Few journalists (18 per cent), however, express a marked interest in local politics, whereas a majority (63 per cent) consider it very important to keep up with developments in national political arenas. 37 per cent also consider it important to keep up with political developments beyond the national policy arenas.

In spite of the fact that 91 per cent of the Danes say they keep up with the news on a day to day basis, this does not necessarily indicate that citizens are strongly involved with what happens in democratic institutions in terms of political phenomena reported by the news media. In other words: Habitual news consumption of political content does not necessarily constitute informed citizenship and participatory performing of public opinion.

\section{Contradictory Expectations}

The crucial challenge facing journalism in representative democracies is that a majority of the public have no more than a lukewarm interest in political affairs. In spite of the fact that credibility in current news coverage is relative high, signs on non-involvement poses serious threats to the institution of journalism acting on behalf of informed citizens (Rosen, 1999)

From the Danish surveys it becomes quite clear that people have high expectations related to the role journalists should play in a democratic society. It is also clear that the journalists in our sample had difficulties living up to these expectations.

A solid majority of all three samples support the idea that journalists should provide information that is in some way useful to their readers, listeners and viewers. Nearly all the sample representing the general public and a clear majority of policymakers consider this function important; they also feel that journalists for the most part succeed in doing this.

These results are surely encouraging for media professionals. Danish journalists apparently manage for the most part in giving the public what it wants. But the results are not necessarily encouraging for Danish democracy. When we ask whether journalists should promote participatory involvement in public affairs, nearly all answer in the affirmative. But only slightly more than half say that journalists actually do so in their day-to-day news reporting.

This contradiction is of both practical and theoretical interest. Researchers and news practitioners alike are currently focused on professional standards under the heading "public journalism" (Glasser, 1998 ), i.e. to promote a sense of community by inspiring commitment in the citizenry via investigative and constructive, problem-solving news stories. Just under three-quarters of all the respondents say that journalists should help the public solve political problems encouraging public participation. But only one-third of the general public and journalists say that news reporting actually does this.

We have also looked at the extent to which Danish journalists live up to the professional norm of neutrality. Over three-fourths of the respondents consider neutrality something to be striven for in news reporting. And we find that many journalists feel that the media perform their duties in an objective fashion - a view shared by only one-third of the other two samples, however.

Although objectivity is the established norm, many Danes are fully aware that news stories are man-made products. Events are framed as raw material according to conventions of the profession. News items are selected among any number of competing phenomena and events. When asked, most respondents feel that journalists should try to position news events in a broader perspective than they actually do today. Three-fourths of the general public and two-thirds of the journalists also feel that 
Figure 3. Public Opinion (in percentage) on what Journalists:

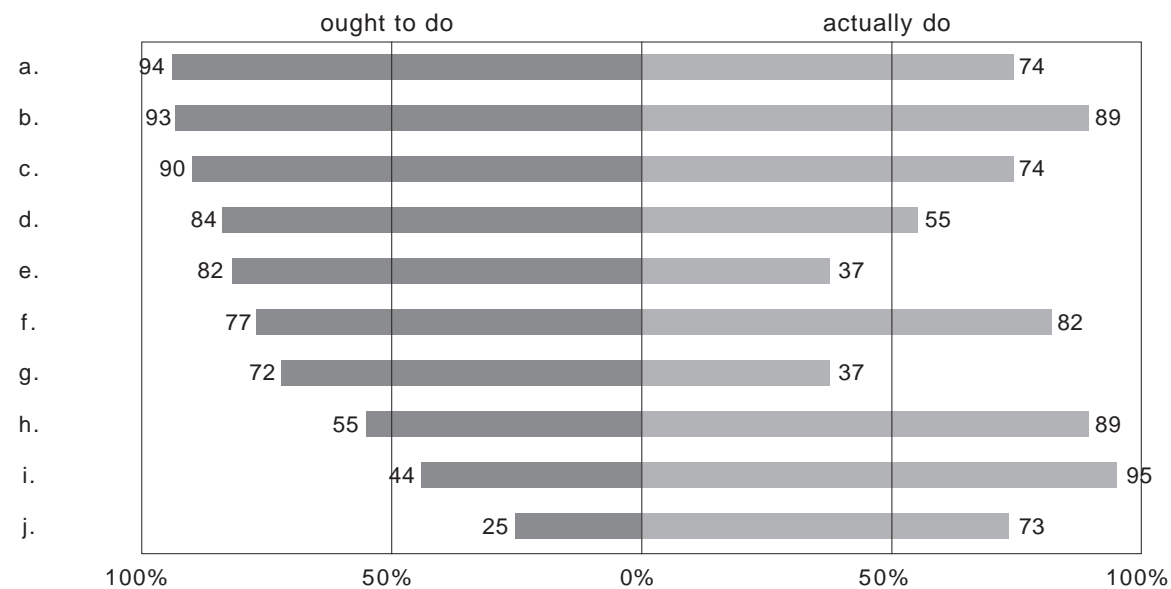

Figure 4. Journalists' Opinion (in percentage) on what Journalists:

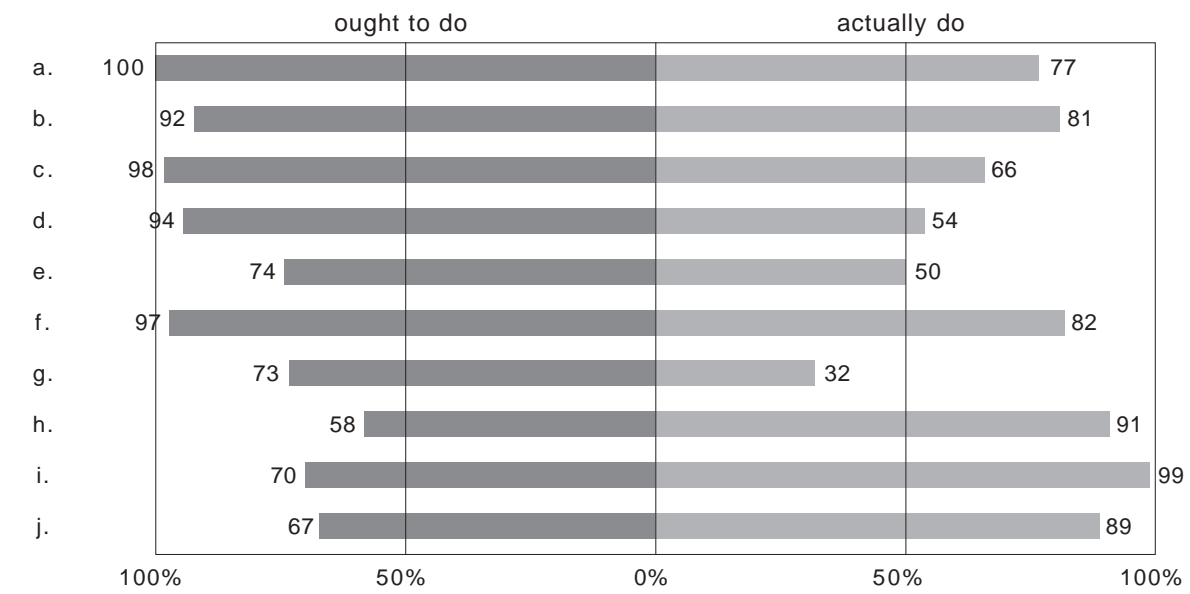

Journalists ought to...

a. Show the consequences of the political decisions to the citizens

b. Provide news you can use

c. Place current events into a larger perspective

d. Promote citizens' involvement in society

e. Remain neutral communicators of what is happening in society

f. Hold politicians responsible for the solution of problems in society

g. Help the citizens to solve problems together

h. Describe the unusual and sensational

i. Compete getting first with the news

j. Set the agenda for political debate

journalists manage to do this quite well. But only a slight majority of policy makers say that news reporting meets their expectations on this point.
As to the role of journalists holding politicians accountable, news media performance in Denmark corresponds better to popular expectations. But 
again we find an interesting difference between responses from the three samples: 77 per cent of the Danish public feel that journalists should hold politicians accountable, 82 per cent say that journalists actually do so. In other words, there would seem to be a certain percentage of the public who feel that journalists do more than they should in this regard.

Even though policy makers may occasionally find themselves under pressure from news reporter watchdogs, 91 per cent of them find it desirable that journalists perform such a function. Somewhat fewer (85 per cent) also feel that journalists perform this function quite well. Journalists, for their part, are unanimous: virtually all value the accountability function highly, but not all are satisfied that journalists succeed in holding politicians accountable for solving social problems.

All in all, differences notwithstanding, there appears to be widespread acceptance of the watchdog function of critical journalism as an integrated part of Danish democracy. A massive majority agrees that news media should serve as independent reporters of current affairs, and three-fourths of the general public feel that journalists for the most part live up to the ideal. A similar share of journalists feel that they are successful on this point, and twothirds of the decision-makers agree with them.

Respondents were also asked about views as to whether or not journalists should focus to unusual and sensational phenomena. A majority of journalists are joined by a slight majority of the population as a whole who answer in the affirmative. Meanwhile, a majority of decision-makers say No. Regardless of whether they approve or disapprove of the practice, roughly 10 per cent of all three groups feel that journalists do serve up sensational items. Thus, here, too, journalists are perceived to do more than they should do.

Another central point on which journalists seem to overestimate the wishes of their audiences concerns the importance of speed in news reporting, of being first to break a story. The vast majority of our respondents say that media do strive to be first, whereas 70 per cent of journalists and 60 per cent of decision-makers find this right and good, only 44 per cent of the Danish people say that speed is an important norm in news production.

Our data indicates that speed of reporting and sensation as professional news values are more highly praised among journalists than among other Danes. In the eyes of the general public, other media functions are more important. Above all, the public values thoroughness and background material, qualities that enable readers, viewers and listeners to form their own opinions as informed citizens on issues of importance to democracy, e.g. financial issues relating to the welfare state and public service.

\section{Three Segments of News Consumers}

Media research has clearly demonstrated that audiences interpret news casting by means of cultural stereotypes producing a variety of meanings and expectations (Jensen, 1998). Our surveys demonstrate that such expectations may not only be regarded as culturally constituted but also as politically ambivalent.

The surveys reported above confirm a relatively low level of news consumption as means for political participation. Only a minority of the Danish citizenry consider it very important to keep abreast of developments in local, national and global politics. Furthermore, ambivalent views are voiced on the power of news media compared to the power of authoritative political institutions.

Basically our findings may be interpreted as striking an uneasy balance between incompatible ideals of direct and representative democracy reflected in professional norms for investigative versus institutional journalism. In terms of news production political agenda setting is no problem among journalists, as long as it is done within professional norms, on behalf of informed citizens. But if major parts of the general public become passive spectators to political agendas, a crisis of legitimacy may threaten democratic ideals of informed public opinion.

The expectations of the Danish respondents may be summed up in this fashion: Critical views are voiced in relation to both news media and political institutions. But at the same time the majority of respondents express acceptance of the predominant ways in which news is produced and distributed paying lip service to democratic ideals of informed citizenship.

Respondents, however, do not always practice what they preach. Hypocrisy is always an option in survey research as well as political life. Our studies indicate that many Danes invest a limited amount of commitment to the current flow of mass mediated politics. Most respondents agree with the statement that it is good for democracy if children grow up in a household that subscribes to a newspaper; but fewer are willing to pay the price of a subscription. Nine respondents in ten say that it is practically a duty as an informed citizen to keep up with the news. Nonetheless, a majority of 57 per cent do not consider it very important to keep abreast of 
developments in politics on the local, national or international level.

The views expressed may be methodologically qualified by taking into account the actual use of news. If we ask a representative sample of Danes what news items reported within a 24-hour period, they consider "important", 26 per cent are unwilling (or unable) to mention a single item on a random day. This quarter of the sample could be termed marginal users of news. In contrast, 51 per cent mentioned two or more news items of importance. They constitute the habitual users of news, while the remaining 23 per cent mention one item only, indicating that the are selective users of news.

In terms of informed citizenship both the former and the latter consumer segments pose potential problems for the traditional ideal of public opinion based democracy. The surveys indicate that a mere half of the Danish population is habitually involved as heavy users of news. And the number is even lower if we consider political news items only.

In short, we have identified relatively large segments of the Danish population who routinely consume political news in a highly selective or superficial fashion. This may not necessarily be regarded as a problem for democracy as institutional govern- ment, e.g. 88 per cent of the Danish population voted in the latest general election. But for the institution of news production and public journalism adhering to ideals of informed citizenship and participation in democratic processes, the surveys must be regarded as a professional challenge.

Lack of political participation could indicate a weakening power of news as an integrated (and integrating) force of political democracy. Furthermore, consumer passivity may legitimate professional power games handled by competing elites, i.e. policymakers and journalists, with little influence left to informed public opinion. In the long run, such trends may weaken the bond between the general population and its political institutions, placing news media in a democratic limbo.

Compared to American research in this field, however, we find that the news media of Denmark still enjoy a fair amount of public trust. We detect a relatively high degree of credibility invested in news consumption, which may in part be interpreted as a proxy for political participation. In spite of the fact that a relatively small number of news consumers actually act as informed citizens between elections, there is no evidence of clear and present danger in terms of political spirals of cynicism.

\section{Note}

1. The study was financed by $\AA$ r 2000 Fonden, Dagspressens Fond, and Pressens Uddannelsesfond. The questionnaire and SPSS-statistics are available on the Internet-address: www.journalism.sdu.dk/forsk ning

\section{References}

Altshull H. (1995) Agents of Power: The Media and Public Policy. New York: Longman.

Berkowitz D. (1997) Social Meanings of News. A TextReader. London: Sage.

Capella J.N., Jamieson K.H. (1997) Spiral of Cynicism: The Press and the Public Good. Oxford: Oxford University Press.

Cook T.E. (1998) Governing with the News: The News Media as a Political Institution. Chicago: The University og Chicago Press.

Curran J., Gurevitch M. (1994) Mass Media and Society. London: Arnold.

Fallows J. (1996) Breaking the News: How the Media Undermine American Democracy. New York: Pantheon.

Glasser T.L. (1999) The Idea of Public Journalism. New York: The Guildford Press.

Habermas J. (1962/1989) The Structural Transformation of the Public Sphere. Cambridge: The MIT Press.

Høyer S. et al. (1982) Maktutredningen: Rapporten om massmedier. Oslo: Statsministeriet.

Iyerger S. (1991). Is Anyone Responsible? How Television Frames Political Issues. Chicago: Chicago University Press.

Jensen K.B. (1998) News of the World: World Cultures Look at Television News. London: Routhledge.

Lippmann W. (1922/1998) Public Opinion. New Brunswick: Transaction Publishers.

Lund A.B. (2001) "The Geneology of News: Researching Journalistic Food Chains". Nordicom Review 2(2001), 15-20.

Lund A.B. (2002) Den redigerende magt - Nyhedsinstitutionens politiske indflydelse. Århus: Aarhus Universitetsforlag.

McNair B. (1995) An Introduction to Political Communication. London: Routhledge.

Petersson O., Carlberg I. (1990) Makten over tanken. Stockholm: Carlssons.

Rogers E.M., Dearing J.W. (1987) “Agenda-Setting Research: Where Has It Been, Where Is It Going?" Communication Yearbook;11:555-594. 
Rosen J. (1999) What Are Journalists for? New Haven: Yale University Press.

Schudson M. (1995) The Power of News. Cambridge: Harvard University Press.
Thompson J.B. (1995) The Media and Modernity: A Social Theory og the Media. Cambridge: Polity Press. 